\title{
PADDY LEAF AILMENTS IDENTIFICATION AND PREDICTIVE MEASURES USING SVM
}

\author{
Likith $\mathrm{G}$ \\ Department of ECE \\ SJBIT, Bangalore, Karnataka, India
}

\author{
Dr. Ravi Kumar A V \\ Department of ECE \\ SJBIT, Bangalore, Karnataka, India
}

\begin{abstract}
Rice is the major sustenance in the globe. However, the quantity of rice is being hindered by different sort of paddy ailments. The peculiar ailment of paddy is the leaf illness. It is actually tedious and relentless for agriculturalist in the remote territories to distinguish the paddy leaf illnesses because of the unavailability of the specialists. Despite of the authorities available in specific locales, identify the ailments by unaided eye which may be inaccurate on some occasions. Therefore, a robotized system can confine these issues. In this paper, a robotized structure is proposed for discovering four essential paddy leaf illnesses (Brown spot, Leaf blast, leaf streak and Bacterial blight) and pesticides or conceivably composts are recommended based on the severeness of the ailments. K-means is utilized for isolating the influenced region of paddy leaf image. Visual substance (colour and texture) are utilized as highlights for grouping of the ailments. The kind of paddy leaf sicknesses is perceived by Support Vector Machine (SVM) classifier. After identification, the prescient cure is suggested based on the severity that can help the horticulture related individuals and associations to take suitable activities against these ailments.
\end{abstract}

Keywords- Paddy Leaf Ailments, K means, Colour, Texture, SVM, and Predictive Measures.

\section{INTRODUCTION}

Rice is a significant horticultural harvest. The majority of the people in the globe consume rice as staple nourishment. Around $92 \%$ of rice is developed and devoured in the east. In India, the populaces expands around 2 percent every year, therefore it is important to expand the cultivation of rice to adapt to the nation's increase in populace. However, agriculturalists lose about $40 \%$ of their rice crops because of vermin and illnesses consistently. There are numerous reasons which decrease the production of rice. The most significant reason is paddy ailments. Generally paddy leaf's are influenced by various kinds of ailments. Ailment identification is a challenging task in today's world.

Generally, ailments are detected physically which is a tough task and is prolonged. The unaided eye view of specialists is the most fundamental methodology embraced practically speaking which is costly on extensive farms. The agriculturists are unaware of right administration to guide the paddy leaf disorders. Most of the farmers determine the ailments physically and they don't know about appropriate administration to fix the paddy leaf aliments. So, the cultivation of rice is restrained each year. For this purpose, a robust paddy leaf ailments identification system and proper predictive measures based on the severeness of ailments becomes a vital task. This paper targets on four most common paddy ailments such as Brown spot, Bacterial blight, Leaf streak and Leaf blast. Brown spot is a fungal disease and in the beginning they are small, round and lesions are dull dark coloured to pink-dark coloured . Leaf blast is a fungiform ailment and lacerations are of axle or oval framed with white or grey centres with red or brown border. Bacterial blight is a bacterial disease and lacerations are creamy coloured with straw-shaded stripes and present close to the edge of the leaf.. Leaf streak is caused by bacteria and lesions are thinner than those of brown spot and it is initially dark green and later becomes light brown to yellowish grey.

In the study carried out by Phadikar et..al., built up a robotized framework to categorize brown_spot and leaf_blast ailment of rice depending on the morphological changes. Otsu's division is utilized to divide the image. Radial distribution was used to extract features to highlight the order of disease.

In the study carried out by Radhika et..al., built up a framework of paddy leaf's ailment detection. They utilized K-_mean's to recognize the contaminated parts of a leaf. Later, GLCM and discrete wavelet transform were utilized in order to extract features from the segmented image. At the end, Back Propagation Neural Network's is used to categorise paddy leaf's ailments.

Another study carried out by R. Islam et..al., built up image processing method to determine the percentage of ailment influenced region of paddy leaf's. Here K_mean's divides the actual image into 3 clusters based on colour. Among the images, influenced and non influenced zone of the leaf were considered to determine the percentage of the influenced region. They determined the overall pixel value of the non influenced and influenced zone. Lastly, the percentage of influenced region is determined. They also noticed the ailment severeness and recommended the suitable predictive measures for the cure of Leaf blast ailment.

The key objectives of this paper are to assemble a database to save paddy leaf's ailment records. Extract features based 
on colour and texture of the paddy leaf. Find out the affected disorder based on ailment inflamed crop pictures by the usage of SVM classifier and $\mathrm{k}$ means grouping is utilized to segment the paddy leaf image.

Image processing techniques are used develop a powerful paddy leaf ailment identification system and also to provide a predictive measure for proper cure.

\section{PROPOSED SYSTEM}

The proposed framework is focused on identifying the paddy leaf's ailments that helps the agriculturists to ensure suitable steps to increase the paddy field yield. The framework has two key parts: Training Part and Testing Part. The developed framework architecture is shown in fig 1.

\section{A.Training Phase}

Some ailments influenced paddy leaf's images are utilized to train the SVM. The steps are;

1) Image-Acquisition's: A few ailments influenced paddy leaf's images are procured from web or captured by digital camera from rice cultivating zones of Karnataka. Some of the sample of each ailment is shown in fig 2.

2) Image-Pre-processing: In this step, the datasets of pictures are pre-processed for additional examination. This progression incorporates the following procedures;

a) Image-resizing: The size of the images are scaled to $[150 * 150]$ for displaying the image and solving the storage issues. The main advantage of resizing is to decrease the computation and complication in the further process.

b) Image filtering: As we know, that image consists of dust, sediment, slob, dew drops and many others when they are captured. The median filter is a nonlinear digital filtering technique which is used to smoothen the pixel and remove the noise. The median is determined by dealing with all the pixel esteems from the encompassing neighbourhood in arithmetical order after which the centre pixel fee is changed.

c) Contrast enhancement: The image contrast is more desirable for higher information of different parts of the photo that includes the normal objects and the wound present in the element of the leaf's.

d) Image-segmentation's: Segmentation's means expressing the image into various clusters which would be simple for analysing the images. In this framework, K_mean's is utilized for partitioning the image, so we can get the ailment influenced region of the paddy leaf's image. Here, image is partitioned into three cluster subjecting on colour variations. Among those clusters, the ailment influenced region is selected in order to extract features. The stages to segment the image is shown below;

Stage1: Resultant image.

Stage2: Convert image from RGB colour space into $\mathrm{L} * \mathrm{a} * \mathrm{~b} *$ colour space.

Stage3: Categorize the colours into $\mathrm{a}^{*} \mathrm{~b} *$ space using K-means.

Stage4: Label every pixel of the image by using the outcome of K-means.

Stage5: Create an image that sections the original image by colour.

Stage6: Separate the affected and unaffected part

Training Phase

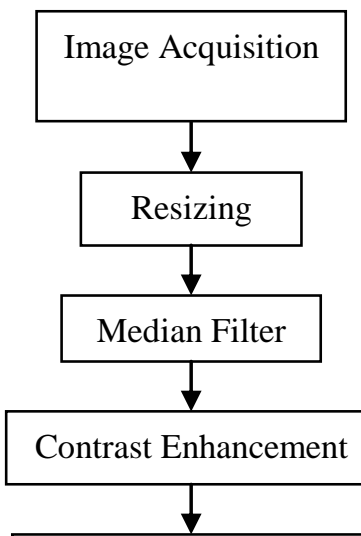

Feature Extraction

(Based on colour and texture)

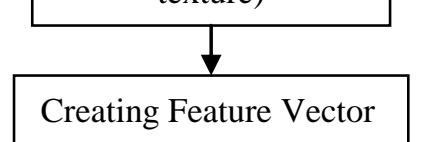

Creating Feature Vector

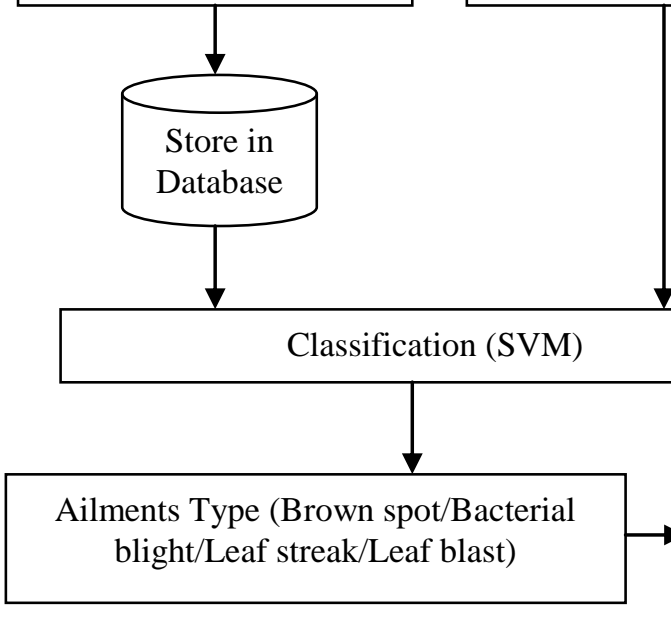

Fig.1. Architecture of the proposed framework

3) Feature Extraction: The extraction of features performs a crucial role in the reduction of dimensionality in image processing. While the information data estimate turns out to be excessively expansive however does not contain the required data. Therefore, in this framework, visual based features are extracted to analyze the image efficiently and produce required information. 
International Journal of Engineering Applied Sciences and Technology, 2019

Vol. 4, Issue 3, ISSN No. 2455-2143, Pages 125-130

Published Online July 2019 in IJEAST (http://www.ijeast.com)

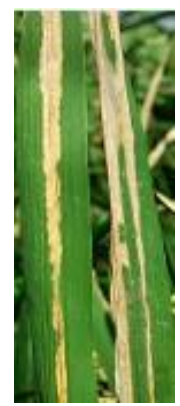

(a)

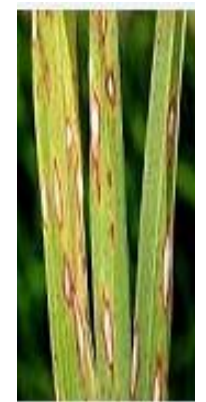

(b)

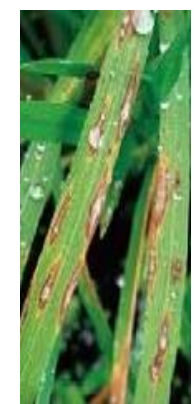

(c)

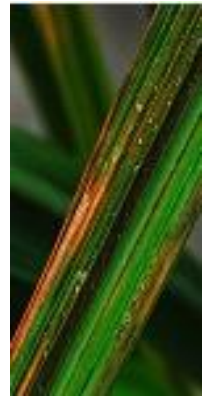

(d)

Fig.2. (a) Bacterial blight (b) Brown spot (c) Leaf blast (d) Leaf streak affected paddy leaf images.

a) Colour features are one of the highlights of the image. Colour moment is one of the most simple and effective method to extract colour features. The colour moments are enough to indicate the colour distribution. The features are evaluated using the following relations;

Mean: It represents the image's normal power level. This could be characterized in different expressions as the total pixel esteems separated with the guide of the entire pixel scope.

$$
\text { mean }=\sum_{i=1}^{L-1} x_{i} p\left(r_{i}\right)
$$

Where, $r_{i}$ represents the power estimation of the picture and $\mathrm{p}\left(\mathrm{r}_{\mathrm{i}}\right)$ is the probability of power estimation of the picture.

RMS Value: Square root of average esteem squares.

$$
R M S=\sqrt{\left(\frac{1}{A B}\right) \sum_{\mathrm{i}=1}^{K} \sum_{j=1}^{K}\left(I_{\mathrm{i} j}-\bar{I}\right)}
$$

Where $I_{i j}$ represents the intensity of the $\mathrm{i}^{\text {th }}$ and $\mathrm{j}^{\text {th }}$ component of the $2 \mathrm{D}$ picture of size A by B. I represent the normal power of entire pixels esteems in the picture.

Variance: It is represented as $\mu_{2}$. It is the amount of complexity of the image.

$$
\mu_{2}(r)=\sum_{i=1}^{L-1}\left(r_{i}-m\right)^{2} p\left(r_{i}\right)
$$

Standard-Deviation: The square root of variance.

$$
\text { Std. deviation }=\sqrt{\text { variance }}
$$

Kurtosis: It is based on the fourth moment and it is the amount of relative levelness of the histogram.

$$
\mu_{4}(r)=\sum_{i=1}^{L-1}\left(r_{i}-m\right)^{a} p\left(r_{i}\right)-3
$$

b) Textures features addresses the presentation of the surface of the image for picture examination. Contrast, Energy, Entropy, Correlation esteems are extracted from the Gray level co-occurrence matrix. These features are evaluated using the following relations;

Contrast: A proportion of a pixel-neighbour force differentiates over the whole picture. The range lies between zero to $(\mathrm{K}-1)^{2}$.

$$
\text { Con }=\sum_{i=1}^{K} \sum_{i=1}^{K}(i-j)^{2} p_{i j}
$$

Where $p_{\mathrm{i} j}$ is the gauge of the likelihood that a couple of focuses satisfying the whole of components of the GLCM and $\mathrm{k}$ is the row (or column) of the square matrix.

Energy: It is termed as consistency. A proportion of consistency will be in the scale of $[0,1]$. Consistency is unity for a steady picture.

$$
E=\sum_{i=1}^{K} \sum_{i=1}^{K} p^{2}
$$

Entropy: It is a factual proportion of arbitrariness to portray the surface of a picture. The entropy is zero when all the pixels regards are zero and it is most extreme when all the pixels regards are identical. The most extreme esteem is $2 \log 2 \mathrm{k}$.

$$
H=-\sum_{\mathrm{i}=1}^{K} \sum_{j=1}^{K} p_{i j} \log _{2} p_{i j}
$$

Correlation: It is the amount of how pixel value is related to its neighbor over the entire picture. The extent of characteristics is one to - one, contrasting with consummate +ve and -ve connections.

$$
\text { Cor }=\sum_{i=1}^{K} \sum_{j=1}^{K} \frac{\left(i-m_{y}\right)\left(j-m_{c}\right) p_{i j}}{\sigma_{y} \sigma_{c}}
$$

4) Generating feature vectors and storage in databank: After extracting the features, a feature vector is generated and stored.

\section{B. Testing Phase}

Experimental images are obtained by camera or from web. The enquiry image is processed and features of the enquiry image are extracted in the similar way carried out during the training phase. Then a feature vector is generated for the enquiry image. Then the generated 
feature vector is directed to the classifier to classify and identify the paddy leaf's ailments.

1) Ailment Categorization using SVM: The paddy leafs ailments are distinguished and perceived utilizing SVM. SVM makes classification by constructing a hyper plane which separates classes of different labels. It classifies the enquiry image to anyone of the paddy leafs ailment. The separating hyper plane equation is,

2)

$$
y=(a * x)+b
$$

Where $\mathrm{a}$ is the load vector and $\mathrm{b}$ is offset.

3) Recommended pesticide or fertilizers: To know the seriousness of the ailment, the zone of entire leafs picture and illness influenced territory of the picture is determined. Then at last, the percentage of the ailments influenced region is calculated using the equation shown below and recommended predictive measures are displayed.

$$
A_{p}=\frac{A_{d}}{A_{\mathbb{l}}} \times 100 \%
$$

Where, $A_{p}$ is the absolute level of the influenced zone, $A_{d}$ is the territory of the ailment influenced part and $A_{\mathbb{}}$ is complete area of a leaf. After calculating the percentage of the affected area, based on that pesticides or fertilizers are displayed.

The recommend fungicides or fertilizers is appeared in Table 1

\section{RESULTS AND DISCUSSIONS}

The work is carried out in 2 stages: Training stage and Testing stage. In training stage, the trained images will be handled into different pre-processing steps. Fig. 3 displays the result after resizing, median filtering and enhancing the contrast of the image.

Fig.4 displays the result of image division using k_mean's. From the 3 clusters, the ailment influenced cluster is selected to extract the features. After extracting the features, the features are stored in the databank.

In the testing stage, the pre-processing, segmentations and feature extractions of the enquiry image is carried out similar to that of the training stage. After generating the feature vector of the enquiry image, the feature vector is delivered to the classifier and the SVM classifies the paddy leafs ailments with the trained datasets.

Then the percentage of the influenced zone is determined and the predictive measures are recommended according to Table 1. The result and predictive measures are shown in fig.5 for the query sample.

\section{TABLE 1. PREDICTIVE MEASURES FOR PADDY

\begin{tabular}{|c|c|c|}
\hline $\begin{array}{l}\text { AILMENT } \\
\text { TYPE }\end{array}$ & $\begin{array}{l}\text { PERCENTAGE OF } \\
\text { AFFECTED } \\
\text { REGION }\end{array}$ & FERTILIZERS OR PESTICIDES \\
\hline \multirow[t]{2}{*}{$\begin{array}{l}\text { BROWN } \\
\text { SPOT }\end{array}$} & LESS THAN $25 \%$ & $\begin{array}{ll}\text { a) } & \text { MONITOR SOIL NUTRIENTS. } \\
\text { b) } & \text { APPLY } \\
& \text { FERTILIZERS. } \\
\text { a) } & \text { APPLY CALCIUM SILICATE } \\
& \text { SLAG PRIOR TO PLANTING } \\
& \text { TO SOIL LOW IN SILICONE. }\end{array}$ \\
\hline & $\begin{array}{l}\text { MORE } \quad \text { THAN } \\
25 \%\end{array}$ & $\begin{array}{l}\text { SHOWERING OF FUNGICIDES, FOR } \\
\text { EXAMPLE, BENZOYL AND IPRODINE } \\
\text { TO THE INFECTED PLANTS AND } \\
\text { ANTI-MICROBIALS, FOR EXAMPLE, } \\
\text { VALIDAMYCIN AND POLYOXIN IS } \\
\text { EFFECTIVE AGAINST THE SICKNESS. }\end{array}$ \\
\hline \multirow[t]{2}{*}{ LEAF BLAST } & LESS THAN 25\% & $\begin{array}{lll}\text { a) } & \text { ADJUST THE SEASON OF } \\
& \text { PLANTING. SOW SEEDS } \\
& \text { EARLY, IF CONCEIVABLE, } \\
& \text { BEFORE THE RAINY } \\
& \text { SEASON STARTS. } \\
\text { a) DIVIDE THE NITROGEN } \\
\text { FERTILIZER INTO TWO OR } \\
\text { MORE } & \text { TREATMENTS. } \\
& \text { EXCESS } & \text { USAGE OF } \\
& \text { FERTILIZER INCREASES } \\
& \text { THE CONCENTRATION OF } \\
& \text { THE BLAST. }\end{array}$ \\
\hline & $\begin{array}{l}\text { MORE THAN } \\
25 \%\end{array}$ & $\begin{array}{l}\text { SILICON MANURES (CA2O4SI) MUST } \\
\text { BE APPLIED TO THE SOIL THAT ARE SI } \\
\text { INADEQUATE TO DIMINISH THE } \\
\text { BLAST. }\end{array}$ \\
\hline \multirow[t]{2}{*}{$\begin{array}{l}\text { BACTERIAL } \\
\text { LEAF } \\
\text { BLIGHT }\end{array}$} & LESS THAN $25 \%$ & $\begin{array}{l}\text { a) USE REQUIRED QUANTITIES } \\
\text { OF PLANT SUPPLIMENTS, } \\
\text { ESPECIALLY N }{ }_{2} \text {. } \\
\text { b) APPLY NITROGEN IN } 3 \\
\text { SPLITS AS, 50\% DURING } \\
\text { INITIAL STAGE, 25\% IN } \\
\text { TILLERING STAGE AND } \\
25 \% \text { IN PANICLE } \\
\text { INITIATION STAGE. }\end{array}$ \\
\hline & $\begin{array}{l}\text { MORE THAN } \\
25 \%\end{array}$ & $\begin{array}{lll}\text { FOLIAR } & \text { SPRINKLE } & \text { OF } \\
\text { STREPTOCYCLINE AND CUSO } & \end{array}$ \\
\hline \multirow[t]{2}{*}{$\begin{array}{l}\text { LEAF } \\
\text { STREAK }\end{array}$} & LESS THAN $25 \%$ & $\begin{array}{l}\text { a) TREAT SEEDS WITH HOT } \\
\text { WATER. } \\
\text { b) USE REQUIRED AMOUNTS } \\
\text { OF PLANT SUPPLEMENTS, } \\
\text { ESPECIALLY NITROGEN. } \\
\text { c) SPRAY FRESH COW DUNG } \\
\text { WATER. }\end{array}$ \\
\hline & $\begin{array}{l}\text { MORE } \\
25 \%\end{array}$ & $\begin{array}{l}\text { A COPPER-BASED FUNGICIDE (COPPER } \\
\text { HYDROXIDE) IS APPLIED FOR } \\
\text { CONTROLLING THE DISEASE. }\end{array}$ \\
\hline
\end{tabular} LEAF AILMENTS}




\section{International Journal of Engineering Applied Sciences and Technology, 2019 \\ Vol. 4, Issue 3, ISSN No. 2455-2143, Pages 125-130 \\ Published Online July 2019 in IJEAST (http://www.ijeast.com)}

(a)
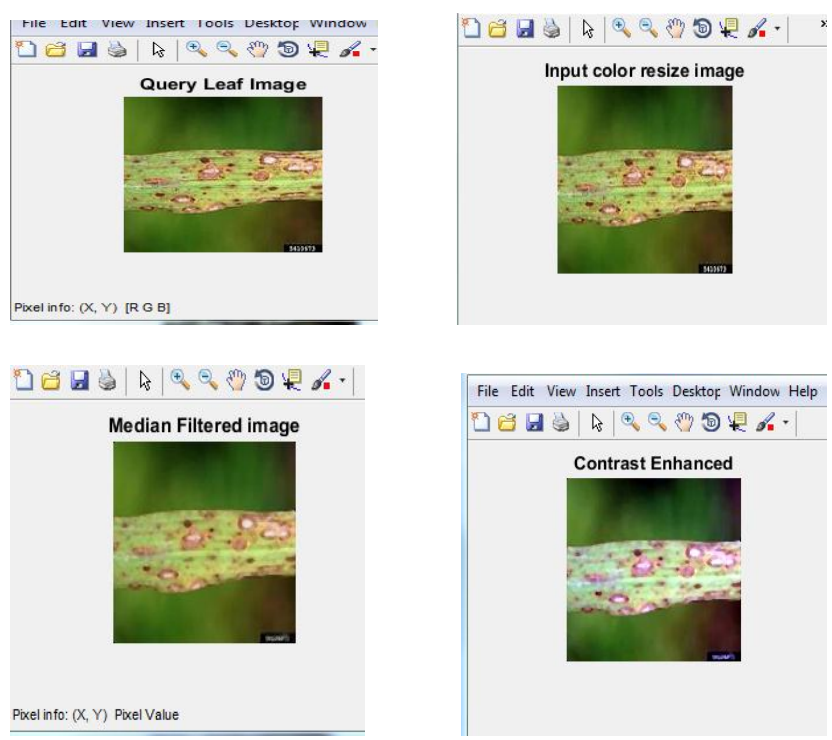

Fig.3. Results after pre-processing

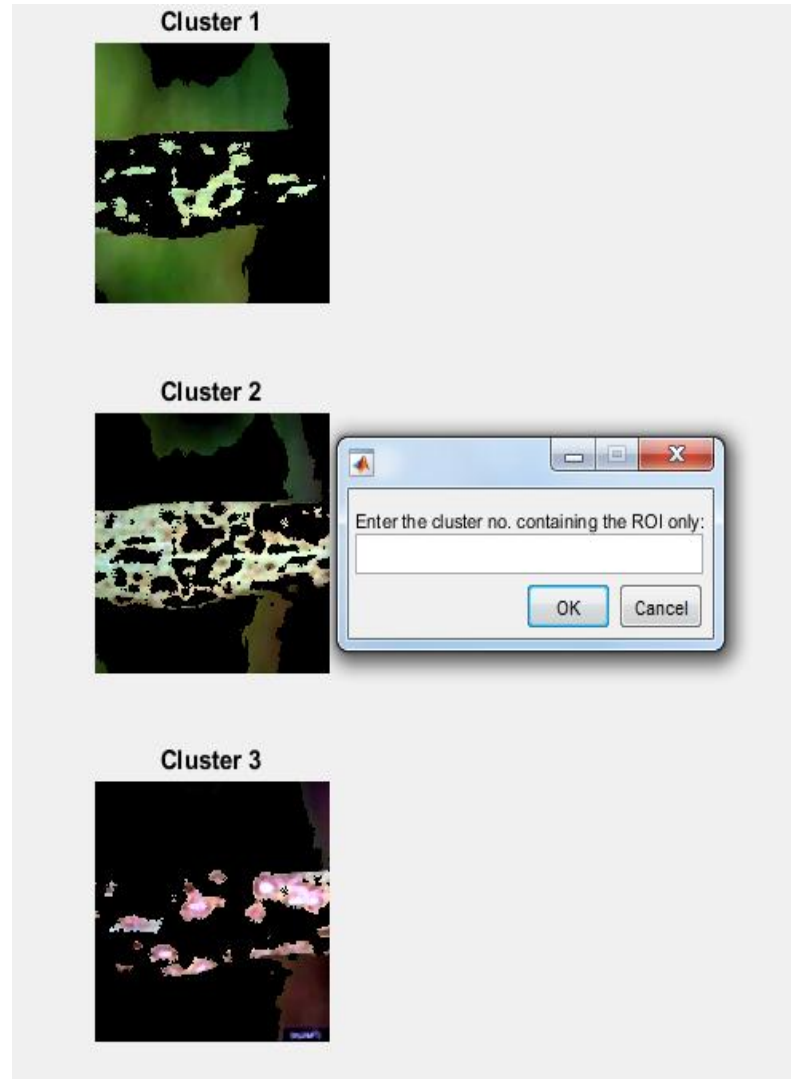

Fig.4. Result of segmentation

The Result is..

$$
\begin{array}{l|l|l}
\square & \square & \mathbb{3} \\
\hline
\end{array}
$$

Leaf_Blast - Severe stage (More than 25\%)

$$
\text { OK }
$$

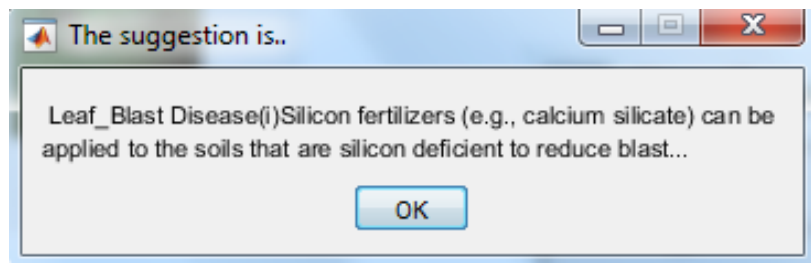

(b)

Fig.5. (a) Identified result (b) Predictive measures obtained based on the severeness of the ailment.

The exactness of every single ailments and complete accuracy of framework is exposed in table 2 . Table 3 displays the performance of this framework with some of the existing frameworks.

TABLE 2. ACCURACY OF THE FRAMEWORK

\begin{tabular}{|c|c|c|}
\hline AILMENT TYPE & ACCURACY(\%) & OVERALL_ACCURACY \\
\hline BROWN_SPOT & 94 & \\
\hline LEAF_BLAST & 92 & \\
\hline BACTERIAL_BLIGHT & 94 & \\
\hline LEAF_STREAK & 93 & \\
\hline HEALTHY_PLANT & $95.6 \%$ \\
\hline
\end{tabular}

TABLE 3. PERFORMANCE COMPARISION

\begin{tabular}{|c|c|}
\hline REFERENCE'S & OVERALL ACCURACY \\
\hline T. SUMAN ET..AL & $70 \%$ \\
$(2015)$ & \\
\hline \multirow{2}{*}{ JOSHI ET..AL } & $87.02 \%$ (USING \\
(2016) & MINIMUM DISTANCE \\
& CLASSIFIER) \\
\cline { 2 - 2 } & 89.23\% (USING K \\
& NEAREST NEIGHBOR \\
CLASSIFIER)
\end{tabular}




\section{International Journal of Engineering Applied Sciences and Technology, 2019 \\ Vol. 4, Issue 3, ISSN No. 2455-2143, Pages 117-119 \\ Published Online July 2019 in IJEAST (http://www.ijeast.com)}

\section{CONCLUSION}

This framework develops a vigorous and a user friendly structure for ailments identification of paddy leaf's. Here, K_mean's is utilized to select ailment influenced section. In order to study the paddy leaf's ailments colour and texture features which are extracted from the ailments influenced section. SVM classifier is used to classify the ailments. The percentage of the influenced zone is determined and fungicides or fertilizers are recommended depending on the severeness of the ailments. We witness that the framework displays a healthy outcome than the existing frameworks.

\section{REFERENCES}

1. M.K. papademetriou*, (2017) Rice production in the Asia-pacific region: issues and perspectives.

2. R. Deshmukh, (2015) "Detection of paddy leaf diseases," International Conference on Advances in Science and Technology, vol. 2, pp. 8-10.

3. A. K. Singh, R. A, and B. S. Raja, (2015) Classification of rice disease using digital image processing and svm," International Journal of Electrical and Electronics Engineers, vol. 7, no. 1, pp. 294\{299.

4. R. Islam and M. R. Islam, (2015) "An image processing technique to calculate percentage of disease affected pixels of paddy leaf," International Journal of Computer Applications, vol. 123, no. 12, pp. 28-34.

5. S. R. N.Neelaveni, (2016) "Paddy leaf disease detection classification and remedy finder using $\mathrm{k}$ means clustering and image mining," International Journal of Computer Applications, vol. 4, no. 12, pp. 20 859-20 866.

6. A. A. Joshi and B. Jadhav, (2016) "Monitoring and controlling rice diseases using image processing techniques," in Computing, Analytics and Security Trends (CAST), International Conference on. IEEE, pp. 471-476.

7. T. Suman and T. Dhruvakumar, (2015) "Classification of paddy leaf diseases using shape and colour features," IJEEE, vol 7, no. 01, pp. 239-250.

8. P. Shah, H. B. Prajapati, and V. K. Dabhi, (2016) \A survey on detection and classification of rice plant diseases," in 2016 IEEE International Conference on Current Trends in Advanced Computing (ICCTAC), March , pp. 1-8.

9. Rong Zhou, Shun"ichi Kaneko, Fumio Tanaka, MiyukiKayamori, Motoshige Shimizu, (2013) "Early Detection And Continuous Quantization Of Plant Disease Using Template Matching And Support Vector Machine Algorithms", First International Symposium On Computing And Networking.

10. John William Orillo, Jennifer Dela Cruz, Leobelle Agapito,Paul Jensen Satimbre Ira Valenzuela,(2013) "Identification Of Diseases In Rice Plant (Oryza Sativa) Using Back Propagation Artificial Neural Network", $7^{\text {th }}$ IEEE International Conference.

11. Amit Kumar Singh, Rubiya, Senthil Raja,(2015) "Classification Of Rice Disease Using Digital Image Processing And SVM Classifier", International Journal of Electrical and Electronics Engineers, Volume 07, Issue 01, June.

12. Wang H, Li G, Ma Z, Li X (2012) “Application of Neural Networks to Image Recognition of Plant Diseases."In:
Proceedings of the 2012 International Conference on Systems and Informatics (ICSAI). IEEE, Yantai, pp 2159-2164 